\title{
Double Hole-Lump Interaction between Halogen Atoms
}

\author{
Darío J. R. Duarte, ${ }^{* \dagger}$ Nélida M. Peruchena, ${ }^{\dagger}$ and Ibon Alkorta ${ }^{\S}$ \\ ${ }^{\dagger}$ Laboratorio de Estructura Molecular y Propiedades, Área de Química Física-Departamento de Química, Facultad de Ciencias Exactas \\ y Naturales y Agrimensura, Universidad Nacional del Nordeste, Avenida Libertad 5460, 3400 Corrientes, Argentina \\ ${ }^{\S}$ Instituto de Química Médica, CSIC, Juan de la Cierva, 3, E-28006 Madrid, Spain
}

\section{Supporting Information}

ABSTRACT: In this paper a theoretical study has been carried out to investigate the nature of the unusual halogenhalogen contacts in the complexes $\mathrm{R}-\mathrm{X} \cdots \mathrm{X}-\mathrm{R}$ (with $\mathrm{R}=-\mathrm{H}$, $-\mathrm{Cl},-\mathrm{F}$ and $\mathrm{X}=\mathrm{Cl}, \mathrm{Br}, \mathrm{I})$. AIM, NBO, and MEP analyses have been used to characterize $\mathrm{X} \cdot \cdots \mathrm{X}$ interactions. Formation of the unusual $\mathrm{X} \cdots \mathrm{X}$ interactions leads to a significant increase of electron charge density in the bonding region between the two halogen atoms. The geometry and stability of these complexes is mainly due to electrostatic interactions lump (X1) $\rightarrow$ hole $(\mathrm{X} 2)$ and lump(X2) $\rightarrow$ hole(X1) [or equivalently $\left[V_{\mathrm{S}, \min }(\mathrm{X} 1) \rightarrow V_{\mathrm{S}, \max }(\mathrm{X} 2)\right.$ and $\left.V_{\mathrm{S}, \min }(\mathrm{X} 2) \rightarrow V_{\mathrm{S}, \max }(\mathrm{X} 1)\right]$ and the charge transfers $\mathrm{LP}(\mathrm{X} 1) \rightarrow \sigma^{*}(\mathrm{R}-\mathrm{X} 2)$ and $\mathrm{LP}(\mathrm{X} 2) \rightarrow$

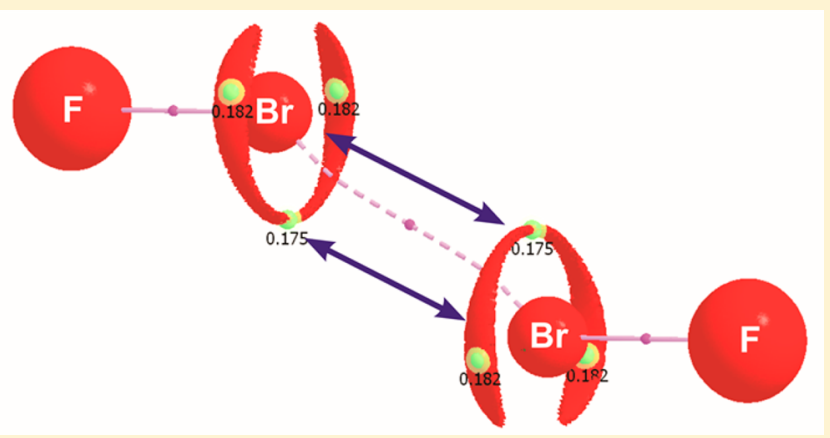
$\sigma^{*}(\mathrm{R}-\mathrm{X} 1)$. In other words, these findings suggest that the electrostatic interactions and the charge transfer play a substantial role in determining the optimal geometry of these complexes, as in conventional halogen bonds, even though the dispersion term is the most important attractive term for all the complexes studied here, save one.

\section{INTRODUCTION}

Halogen bonding is a net attractive interaction between an electrophilic region associated with a halogen atom in a molecular entity and a nucleophilic region in another, or the same, molecular entity. ${ }^{1}$ In general, these interactions can be symbolized as $\mathrm{R}-\mathrm{X} \cdots \mathrm{B}$, in which $\mathrm{X}$ is an electrophilic halogen atom ( $\mathrm{I}, \mathrm{Br}, \mathrm{Cl}$, and $\mathrm{F}$ to a lesser extent), $\mathrm{R}$ is a monovalent substituent, and $\mathrm{B}$ is a Lewis base. ${ }^{2-4}$

Moreover, it has long been known that halogen atoms do participate in halogen-halogen $(\mathrm{X} \cdots \mathrm{X})^{5-7}$ interactions that appear to play a significant role in determining the crystal structure. Extensive studies show that there are two types of angular arrangements for $\mathrm{X} \cdots \mathrm{X}$ interactions. ${ }^{8}$ The first possibility occurs when $\theta_{1} \cong \theta_{2}$, and the second possibility is when $\theta_{1} \cong 180^{\circ}$ and $\theta_{2} \cong 90^{\circ}$ (Scheme 1). This last arrangement is simply a conventional halogen bond, whereas that for the $\mathrm{X} \cdots \mathrm{X}$ interactions of type $\mathrm{I}$ is believed to be a result of close packing in the solid state. 910

$\mathrm{X} \cdots \mathrm{X}$ interactions have been used to develop new materials and to explain the geometric arrangement of other important

Scheme 1. Two Preferred Geometries for Halogen-Halogen Contacts: Type I, $\theta_{1} \cong \theta_{2}$ and Type II, $\theta_{1} \cong 180^{\circ}, \theta_{2} \cong 90^{\circ}$

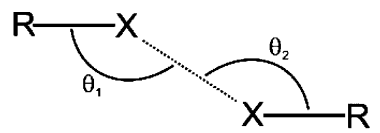

(I)

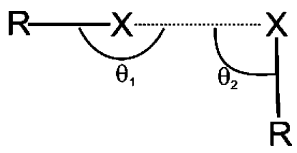

(II) materials. ${ }^{11,12}$ One example is the use of $\mathrm{Cl} \cdots \mathrm{Cl}$ interactions to prepare highly stereoregular organic polymers. ${ }^{13}$

We have recently shown that (in conventional halogen bonds) the electrostatic forces and charge transfer play an important role not only in the stabilization of the complex but also in the conformation of the molecular geometry of equilibrium. $^{14,15}$ That is to say, the strong directional preferences of a halogen bond arise from the tendency to maximize the main two directional attractive contributions to the interaction energy, i.e., electrostatics and charge transfer. In addition, this and other articles have shown that the hole-lump concept provides important answers on the characteristics of the XBs. ${ }^{14-17}$

Most of the studies on $\mathrm{X} \cdots \mathrm{X}$ interactions in the literature are restricted to conventional halogen bonds, whereas $\mathrm{X} \cdots \mathrm{X}$ interactions (type I) have received less attention especially from a theoretical point of view. Awwadi et al. in a study of X... $\mathrm{X}$ contacts (type I and type II) in organic compounds using $\mathrm{ab}$ initio calculations and the results of previously reported crystallographic studies showed that these interactions are controlled by electrostatics. ${ }^{18}$

On the contrary, a new type of Lewis acid-base interactions has recently been reported in the framework of a pnicogen bond $\left(\mathrm{H}_{2} \mathrm{XP} \cdots \mathrm{PXH}_{2}\right.$, for $\mathrm{X}=-\mathrm{H},-\mathrm{CH}_{3},-\mathrm{NH}_{2},-\mathrm{OH},-\mathrm{F}$, and $\left.-\mathrm{BH}_{2}\right){ }^{19}$ In these interactions it was observed that both $\mathrm{H}_{2} \mathrm{XP}$ molecules are electron-pair donors and acceptors via

Received: November 6, 2014

Revised: March 29, 2015

Published: March 31, 2015 
$\mathrm{LP}(\mathrm{P} 1) \rightarrow \sigma^{*}(\mathrm{P} 2-\mathrm{X})$ and $\mathrm{LP}(\mathrm{P} 2) \rightarrow \sigma^{*}(\mathrm{P} 1-\mathrm{X})$ chargetransfer interactions. ${ }^{20}$

Eskandari et al. through the Laplacian of electron density showed that the noncovalent $\mathrm{P} \cdots \mathrm{P}, \mathrm{P} \cdots \mathrm{N}$, and $\mathrm{N} \cdots \mathrm{N}$ interactions can be categorized as hole-lump interactions. According to these authors, a region of charge depletion and excess kinetics energy (hole) in the valence shell charge concentration (VSCC) of pnicogen atom combines with a region of charge concentration and excess potential energy (lump) in the VSCC of another molecule and forms a pnicogen bond. $^{21}$

Moreover, it is well-known that the conventional halogen bonds tend toward a linear or nearly linear $\mathrm{R}-\mathrm{X} \cdots \mathrm{Y}$ alignment. Even more, according to IUPAC in its recent interim definition, ${ }^{1}$ it indicates that "The angle $\mathrm{R}-\mathrm{X} \cdots \mathrm{Y}$ tends to be close to $180^{\circ}$, i.e., the halogen bond acceptor $\mathrm{Y}$ approaches $\mathrm{X}$ along the extension of the $\mathrm{R}-\mathrm{X}$ bond". In the complexes studied here it can be observed that the equilibrium angle R$\mathrm{X} \cdots \mathrm{X}$ is close to $150^{\circ}$, so one wonders, are the halogenhalogen contacts type I conventional halogen bond? What is the nature of these interactions? What role does the charge transfer and the electrostatic interaction play in the determination of the molecular geometry? We believe that a deep study of the electronic redistribution mechanisms that occur during the attractive $\mathrm{X} \cdots \mathrm{X}$ interaction is essential to understand the nature of these interactions.

\section{COMPUTATIONAL DETAILS}

The geometries of all the monomers and complexes were fully optimized using the Møller-Plesset second-order perturbation theory ${ }^{22}$ with the aug-cc-pVTZ basis set. ${ }^{23}$ For the iodine atom, the Def2-TZVP basis set was used. ${ }^{24}$ Recent reports have indicated that the uncorrected interaction energy with large basis sets provides a better estimate than the BSSE corrected one using the counterpoise method. ${ }^{25,26}$ Some test calculations (Table S1 of the Supporting Information) with the aug-ccpVQZ and aug-cc-pV5Z basis sets confirm previous findings. Thus, in the present article the uncorrected MP2/aug-cc-pVTZ interaction energy will be used.

The localized molecular orbital energy decomposition analysis (LMOEDA) partition method ${ }^{27}$ at the MP2 computational level has been used to compute the interaction energy terms using eq 1 .

$$
E_{\mathrm{i}}=E_{\mathrm{ele}}+E_{\mathrm{ex}-\mathrm{rep}}+E_{\mathrm{pol}(\mathrm{LMOEDA})}+E_{\mathrm{disp}}
$$

where $E_{\text {ele }}$ is the electrostatic term describing the classical Coulomb interaction of the occupied orbitals of one monomer with those of another monomer and $E_{\text {ex-rep }}$ is the attractive exchange component resulting from the Pauli exclusion principle and the interelectronic repulsion. $E_{\text {pol(LMOEDA) }}$ and $E_{\text {disp }}$ correspond to polarization and dispersion terms, respectively. In addition, the $E_{\mathrm{pol}(\mathrm{LMOEDA})}$ have been decomposed in the charge-transfer energy, $E_{\mathrm{ct}}$ and the rest of the polarization, $E_{\mathrm{pol}}$, following the reduced variational space (RVS) formalism. ${ }^{28}$ These calculations have been carried out with the GAMESS program (version 2013-R1). ${ }^{29}$

The intermolecular distribution of both the electronic charge density and $L(\mathbf{r})=-{ }^{1} /{ }_{4} \nabla^{2} \rho(\mathbf{r})$ function has been studied within the framework of the atoms in molecules (AIM) theory ${ }^{30}$ with the AIMAll program, ${ }^{31}$ with the electron density obtained at B3LYP level ${ }^{32}$ with the $6-311 \mathrm{G}(\mathrm{d}, \mathrm{p})$ basis $\operatorname{set}^{33}$ using the MP2/aug-cc-pVTZ optimized geometry. The B3LYP/6-311G(d,p) computational level allows us to analyze the electron density of the systems using a full electron description in all cases. The electron density shift upon complex formation has been evaluated as the difference between the electron density of the complex and that of the isolated monomers at their geometry in the complex.

The natural bond orbital (NBO) method ${ }^{34}$ has been used to analyze the stabilizing charge-transfer interactions in the dimers. NBO analysis was performed with the NBO 3.1 program, ${ }^{35}$ as implemented in the Gaussian $03 .{ }^{36}$ Electrostatic potentials (i.e., most positive, $V_{\mathrm{S}, \max }$ and most negative, $V_{\mathrm{S}, \min }$, values) for all isolated monomers were computed at B3LYP/6$311 \mathrm{G}(\mathrm{d}, \mathrm{p})$ level of theory with the Multiwfn program. ${ }^{37}$

\section{RESULTS AND DISCUSSION}

Geometrical and Energetic Parameters. Table 1 reports selected geometric parameters and the interaction energies of

Table 1. Selected Geometric Parameters and Interaction Energies $^{a}$

$\begin{array}{lcccc}\text { complexes } & d(\mathrm{X} \cdots \mathrm{X}) & r_{\mathrm{vdW}}(\mathrm{X}+\mathrm{X})^{b} & \theta(\mathrm{R}-\mathrm{X} \cdots \mathrm{X}) & \Delta E \\ \mathrm{HCl} \cdots \mathrm{ClH} & 3.553 & 3.50 & 150.96 & -2.9 \\ \mathrm{ClCl} \cdots \mathrm{ClCl} & 3.214 & 3.50 & 147.21 & -6.5 \\ \mathrm{FCl} \cdots \mathrm{ClF} & 3.126 & 3.50 & 144.27 & -5.4 \\ \mathrm{HBr} \cdots \mathrm{BrH} & 3.634 & 3.70 & 149.28 & -6.3 \\ \mathrm{ClBr} \cdots \mathrm{BrCl} & 3.183 & 3.70 & 147.30 & -12.3 \\ \mathrm{BrBr} \cdots \mathrm{BrBr} & 3.186 & 3.70 & 148.90 & -13.8 \\ \mathrm{FBr} \cdots \mathrm{BrF} & 2.952 & 3.70 & 145.84 & -13.6 \\ \mathrm{HI} \cdots \mathrm{IH} & 3.917 & 3.96 & 146.83 & -6.4 \\ \mathrm{II} \cdots \mathrm{II} & 3.366 & 3.96 & 149.40 & -17.9 \\ \mathrm{BrI} \cdots \mathrm{IBr} & 3.309 & 3.96 & 147.03 & -17.8 \\ \mathrm{ClI} \cdots \mathrm{ICl} & 3.273 & 3.96 & 146.22 & -17.3 \\ \mathrm{FI} \cdots \mathrm{IF} & 3.025 & 3.96 & 144.48 & -22.9\end{array}$

${ }^{a} d(\mathrm{X} \cdots \mathrm{X})$ : intermolecular distances $(\AA) . r_{\mathrm{vdW}}(\mathrm{X}+\mathrm{X})$ : sum of the van der Waals radii of interacting atoms $(\AA) . \theta$ in degrees (deg). $\Delta E$ : interaction energies $\left(\mathrm{kJ} \mathrm{mol}^{-1}\right)$. ${ }^{b}$ Radii were taken from ref 38 .

the studied complexes. It can be seen that in most cases (except in $\mathrm{HCl} \cdots \mathrm{ClH}$ complex), $\mathrm{X} \cdots \mathrm{X}$ intermolecular distances are substantially shorter than the sum of the van der Waals radii ${ }^{38}$ of the halogen atoms. The short intermolecular distances are caused by the attraction of the molecules that produce an overlap of the molecular orbitals.

The crystal structure of the solid $\mathrm{Cl}_{2}, \mathrm{Br}_{2}$, and $\mathrm{I}_{2}$ are available in the literature but in the three cases, the molecules adopt a disposition that corresponds to halogen bond of type II $\left(\theta_{1} \cong\right.$ $170^{\circ}$ and $\left.\theta_{2} \cong 103^{\circ}\right) \cdot{ }^{39,40}$ The intermolecular distances in the solid phase are always slightly larger than those reported here, $3.330,3.367$, and $3.500 \AA$, respectively.

The interaction energies of the homodimers lie between -2.9 and $-22.9 \mathrm{~kJ} \mathrm{~mol}^{-1}$, a range that is comparable to the interaction energies of conventional halogen bonded complexes. ${ }^{4}$ It is interesting to note that the weakest complexes correspond to those where the interacting halogen atoms are bound to an atom with low electron-withdrawing capacity (for instance, hydrogen).

The calculated interaction energy terms with the LMOEDA methodology have been gathered in Table 2. In all the cases, the most important stabilization term corresponds to the dispersion followed by the electrostatic term, in agreement with a previous report ${ }^{41,42}$ save in the strongest complex FI...IF, where the electrostatic term is slightly more important than the charge-transfer and the dispersion ones. The analysis of the 
Table 2. Energy Terms of the Interaction Energy Obtained with the LMOEDA Methodology ${ }^{a}$

\begin{tabular}{lrrrrr} 
complexes & $E_{\text {ele }}$ & $E_{\text {ex-rep }}$ & $E_{\mathrm{pol}^{\prime}}$ & \multicolumn{1}{c}{$E_{\mathrm{ct}}$} & $E_{\text {disp }}$ \\
$\mathrm{HCl} \cdots \mathrm{ClH}$ & -1.4 & 4.3 & -0.1 & -0.4 & -5.2 \\
$\mathrm{ClCl} \cdots \mathrm{ClCl}$ & -5.4 & 13.8 & -0.6 & -2.6 & -11.6 \\
$\mathrm{FCl} \cdots \mathrm{ClF}$ & -6.2 & 17.0 & -1.5 & -3.9 & -10.9 \\
$\mathrm{HBr} \cdots \mathrm{BrH}$ & -3.9 & 9.1 & -0.2 & -1.1 & -10.2 \\
$\mathrm{ClBr} \cdots \mathrm{BrCl}$ & -14.6 & 37.6 & -2.7 & -8.5 & -24.0 \\
$\mathrm{BrBr} \cdots \mathrm{BrBr}$ & -15.1 & 38.3 & -1.1 & -9.2 & -26.7 \\
$\mathrm{FBr} \cdots \mathrm{BrF}$ & -26.4 & 71.3 & -8.0 & -19.3 & -31.2 \\
$\mathrm{HI} \cdots \mathrm{IH}$ & -5.6 & 12.6 & -0.3 & -1.9 & -11.3 \\
$\mathrm{II} \cdots \mathrm{II}$ & -21.2 & 62.0 & -3.3 & -19.5 & -36.0 \\
$\mathrm{ClI} \cdots \mathrm{ICl}$ & -27.5 & 78.5 & -6.3 & -28.5 & -34.1 \\
$\mathrm{BrI} \cdots \mathrm{IBr}$ & -25.9 & 72.9 & -4.8 & -26.8 & -32.7 \\
$\mathrm{FI} \cdots \mathrm{IF}$ & -55.2 & 153.3 & -18.5 & -52.7 & -49.8
\end{tabular}

${ }^{a}$ The $E_{\mathrm{Pol}^{\prime}}$ and charge-transfer terms, $E_{\mathrm{ct}}$ have been calculated with the RVS approach.

polarization shows that the charge-transfer term is the dominant one being always larger than the rest of the terms.

The complexes with the smaller interaction energies show the larger contribution of the dispersion, whereas as the interaction energy increases, the contribution of the electrostatic term to the stabilization energy increases.

Electron Charge Density Analysis. The topological analysis of the electron density shows the presence of a bond critical point (BCP) and a corresponding bond path, which links the interacting halogen atoms. Table 3 gathers the values

Table 3. Local Topological Properties of the Electron Charge Density at the X $\cdots X$ Interaction $\mathrm{BCP}^{a}$

$\begin{array}{lcccc}\text { complexes } & \rho\left(\mathbf{r}_{\mathrm{b}}\right) & L\left(\mathbf{r}_{\mathrm{b}}\right) & H\left(\mathbf{r}_{\mathrm{b}}\right) & V_{\mathrm{e}-\mathrm{n}}\left(\mathbf{r}_{\mathrm{b}}\right) \\ \mathrm{HCl} \cdots \mathrm{ClH} & 0.005 & -0.005 & 0.001 & -0.050 \\ \mathrm{ClCl} \cdots \mathrm{ClCl} & 0.009 & -0.010 & 0.002 & -0.153 \\ \mathrm{FCl} \cdots \mathrm{ClF} & 0.011 & -0.011 & 0.002 & -0.156 \\ \mathrm{HBr} \cdots \mathrm{BrH} & 0.006 & -0.006 & 0.001 & -0.130 \\ \mathrm{ClBr} \cdots \mathrm{BrCl} & 0.015 & -0.012 & 0.002 & -0.427 \\ \mathrm{BrBr} \cdots \mathrm{BrBr} & 0.015 & -0.012 & 0.002 & -0.499 \\ \mathrm{FBr} \cdots \mathrm{BrF} & 0.024 & -0.017 & 0.001 & -0.680 \\ \mathrm{HI} \cdots \mathrm{IH} & 0.007 & -0.005 & 0.001 & -0.202 \\ \mathrm{II} \cdots \mathrm{II} & 0.019 & -0.010 & 0.000 & -0.901 \\ \mathrm{BrI} \cdots \mathrm{IBr} & 0.021 & -0.011 & 0.000 & -0.908 \\ \mathrm{ClI} \cdots \mathrm{ICl} & 0.023 & -0.011 & -0.001 & -0.908 \\ \mathrm{FI} \cdots \mathrm{IF} & 0.038 & -0.013 & -0.005 & -1.507\end{array}$

${ }^{a} \rho\left(\mathbf{r}_{\mathrm{b}}\right)$ : electron density (au). $L\left(\mathbf{r}_{\mathrm{b}}\right)=-1 / 4 \nabla^{2} \rho\left(\mathbf{r}_{\mathrm{b}}\right) \quad(\mathrm{au}) . \quad V_{\mathrm{e}-\mathrm{n}}\left(\mathbf{r}_{\mathrm{b}}\right)$ : electron-nuclear attractive contribution to virial field $(\mathrm{au}) . H\left(\mathbf{r}_{\mathrm{b}}\right)$ : total electronic energy density (au).

of the local topological parameters at $\mathrm{X} \cdots \mathrm{X}$ bond critical points (BCPs) obtained from the AIM analyses. The electron density values range from 0.005 to $0.038 \mathrm{au}$, and the $L\left(\mathbf{r}_{\mathrm{b}}\right)$ ranges from -0.005 to $-0.017 \mathrm{au}$, which are similar to the values reported for other halogen bond interactions. ${ }^{14-17}$ These values indicate that the observed interactions are within the closed shell regime.

The signs of the $L\left(\mathbf{r}_{\mathrm{b}}\right)$ function and $H\left(\mathbf{r}_{\mathrm{b}}\right)$ at the X $\cdots \mathrm{X}$ BCPs can be used to characterize the nature of these interactions. $L\left(\mathbf{r}_{\mathrm{b}}\right)<0$, whereas $H\left(\mathbf{r}_{\mathrm{b}}\right)>0$ for the more weakly bound dimers, but $H\left(\mathbf{r}_{\mathrm{b}}\right)$ is scarcely negative for the $\mathrm{CII} \cdots \mathrm{ICl}$ and $\mathrm{FI} \cdots$ IF complexes. Thus, these last interactions can be described as interactions of moderate strength with partial covalent character. $^{43}$

The electron-nuclear attractive contribution to virial field measured at the $\mathrm{X} \cdots \mathrm{X} \mathrm{BCP},\left|V_{\mathrm{e}-\mathrm{n}}\left(\mathbf{r}_{\mathrm{b}}\right)\right|$, is a measure of the electrostatic force exerted by the nuclei $\mathrm{X}$ on the electronic cloud of the intermolecular region. Figure 1 shows a good

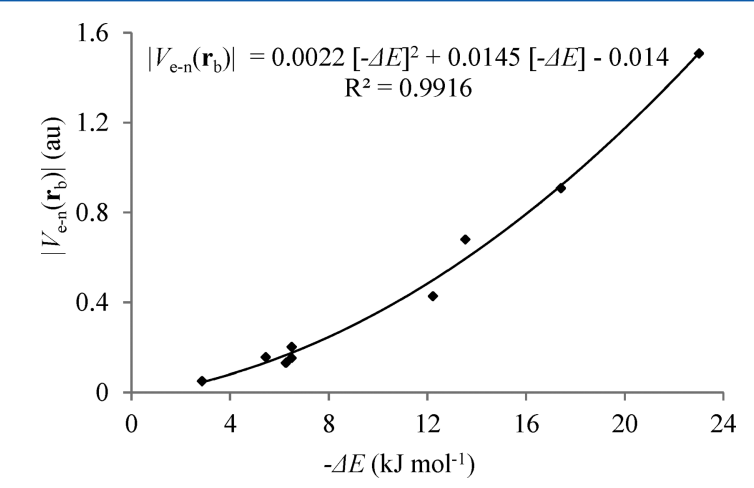

Figure 1. Correlation between $\left|V_{\mathrm{e}-\mathrm{n}}\left(\mathbf{r}_{\mathrm{b}}\right)\right|$ and interaction energies.

quadratic relationship between $\left|V_{\mathrm{e}-\mathrm{n}}\left(\mathbf{r}_{\mathrm{b}}\right)\right|$ and the interaction energies. Therefore, the electrostatic interaction between the electron cloud of the intermolecular region and the nucleus of the halogen atoms play a key role in stabilizing these complexes.

Accumulation of electron charge density at the intermolecular region $\mathrm{X} \cdots \mathrm{X}$ is an indicator of the existence of an attractive interaction. ${ }^{44,45}$ Figure $2 \mathrm{~A}$ shows the electron density

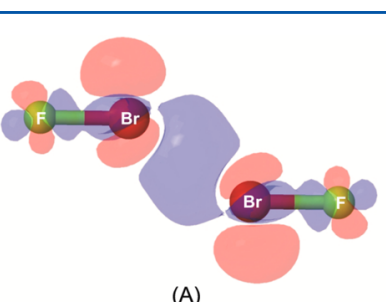

(A)

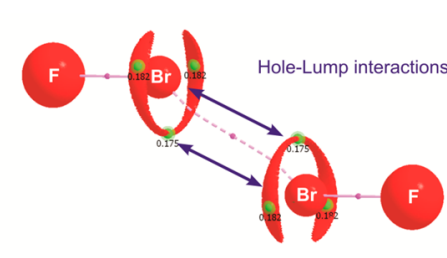

(B)
Figure 2. (A) Electron density shifts for $\mathrm{FBr} \cdots \mathrm{BrF}$ at the \pm 0.0005 au isosurface. Red and blue regions indicate regions of decreased and increased electron densities, respectively. (B) Envelope at $L(\mathbf{r})=0.014$ au for $\mathrm{FBr} \cdots \mathrm{BrF}$. The values of $\rho(\mathbf{r})$ in au at the CPs $(3,-3)$ of $L(\mathbf{r})$ are indicated (green dots). The bond path are bond critical pints are indicated with continuous and dashed lines and pink dots.

shifts for $\mathrm{FBr} \cdots \mathrm{BrF}$ complex. It can be seen that there is a significant building up of the electron density in the region between the two bromine atoms. In addition, Figure $2 \mathrm{~A}$ illustrates the increase in electron density in that region, and at the region of the $\mathrm{F}-\mathrm{Br}$ bond. Electron density loss is experienced in the region near the two bromine nuclei, and to a lesser extent in the region near the two fluorine nuclei. It is the buildup of charge in the region between the two $\mathrm{Br}$ nuclei that results in the formation of this particular halogen bond.

The $L(\mathbf{r})=-{ }^{1} /{ }_{4} \nabla^{2} \rho(\mathbf{r})$ function shows the regions of the space where the electron density is locally concentrated $[L(\mathbf{r})>$ $0]$ or depleted $[L(\mathbf{r})<0] .^{46}$ Recently, this function has been used to characterized various noncovalent molecular interactions that involving to $\sigma$-hole concept. ${ }^{14,15,47-49}$ According to the hole-lump theory the areas with charge concentration on the halogen bond acceptors $[L(\mathbf{r})>0]$ interact with the charge depleted areas of the halogen bond donor $[L(\mathbf{r})<0]$. Figure $2 \mathrm{~B}$ shows that the molecules are oriented so that a maximum 
critical point $(3,-3)$ of $L(\mathbf{r})$ in the VSCC of one of the bromine atom is aligned with the $\sigma$-hole in the VSCC of the other bromine atom and vice versa. In other words, the $L(\mathbf{r})$ function reveals a double hole-lump interaction between both bromine atoms.

The $L(\mathbf{r})$ function in the isolated $\mathrm{BrF}$ molecule shows four degenerate CPs $(3,-3)$ on the VSCC of the bromine atom with an electronic density of 0.180 au (Figure S1 of the Supporting Information). In the $\mathrm{FBr} \cdots \mathrm{BrF}$ complex, only three CPs $(3,-3)$ of $L(\mathbf{r})$ in each $\mathrm{Br}$ atom. The values of the electron density in the CP located in the molecular plane are smaller $(0.175 \mathrm{au})$ than the electronic density at the CPs $(3,-3)$ of $L(\mathbf{r})$ that are out of the plane $(0.182 \mathrm{au})$. That is, complex formation causes a loss of electronic density in the molecular plane of the VSCC and an increase of electronic density on the VSCC of the bromine atom out of the molecular plane relative to the isolated monomer.

NBO Analyses. The second-order NBO perturbation analysis provides an evaluation of the stabilization energy due to charge transfer from the lone pairs of X1 to the $\sigma^{*}(\mathrm{R}-\mathrm{X} 2)$ orbital and from the lone pairs of X2 to the $\sigma^{*}(\mathrm{R}-\mathrm{X} 1)$ orbital (Figure 3 ). Due to the symmetry of the systems, only the
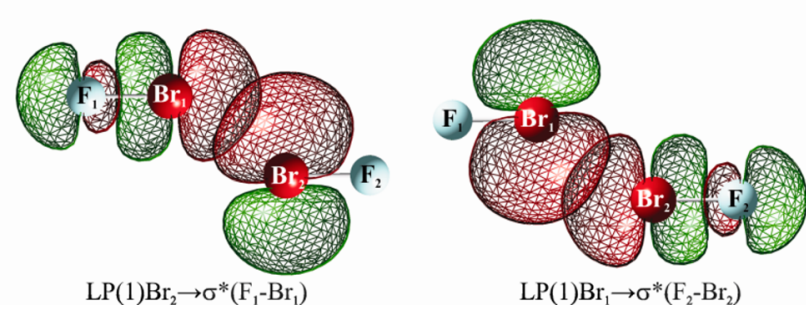

Figure 3. Simultaneous hyperconjugation of the occupied lone pair of electrons of the bromine atoms $\mathrm{LP}(\mathrm{Br})$ with the unoccupied antibonding orbital $\sigma^{*}(\mathrm{~F}-\mathrm{Br})$.

charge transfer from molecule-1 toward molecule-2 will be considered. These results are reported in Table 4. These charge-transfer energies follows the order $\mathrm{H}-\mathrm{X} \cdots \mathrm{X}-\mathrm{H}<\mathrm{Cl}-$ $\mathrm{X} \cdots \mathrm{X}-\mathrm{Cl}<\mathrm{F}-\mathrm{X} \cdots \mathrm{X}-\mathrm{F}$ (for the same $\mathrm{X}$ ). That is, the same order that the electronegativities of the substituents $\mathrm{H}, \mathrm{Cl}$, and F.

The NBO analysis shows that electron transfer from the $\mathrm{LP}(1) \mathrm{X} 1$ to the $\sigma^{*}(\mathrm{R}-\mathrm{X} 2)$ orbital is smaller than the one from the $\mathrm{LP}(2) \mathrm{X} 1$ to the $\sigma^{*}(\mathrm{R}-\mathrm{X} 2)$. This is due to the spatial arrangement of the molecular orbitals $\mathrm{LP}(1) \mathrm{X} 1, \mathrm{LP}(2) \mathrm{X} 1$, and $\sigma^{*}(\mathrm{R}-\mathrm{X} 2)$. In other words, $\mathrm{NBO}$ analysis shows that electron transfer is produced in both directions, from the lone pairs on $\mathrm{X} 1$ to the $\sigma^{*}(\mathrm{R}-\mathrm{X} 2)$ orbital, and from the lone pairs on $\mathrm{X} 2$ to the $\sigma^{*}(\mathrm{R}-\mathrm{X} 1)$ orbital. The amount of charge transfer in both directions is always equivalent in each of the complexes. The comparison of the charge-transfer stabilization energies obtained with the RVS method (Table 2) and the NBO (Table 4) shows that the contribution of the latter ones are on average 3 times the former. Thus, care should be taken when similar terms obtained with different energy partition methodologies are compared. In any case, a good linear correlation is obtained between the data obtained with the two partition methods $\left(R^{2}=0.98\right)$, an indication that a similar trend is observed within the compounds studied.

The LP's of X1 and X2 can be associated with their nonbonding $\mathrm{p}_{x}$ and $\mathrm{p}_{y}$ orbitals whereas the $\sigma^{*}{ }_{\mathrm{R}-\mathrm{X}}$ is roughly the negative overlap of the $\mathrm{p}_{z}(\mathrm{R})$ and $\mathrm{p}_{z}(\mathrm{X}) .^{50}$

Figure 4 shows an excellent lineal relationship between $\Delta \mathrm{LP}(2) \mathrm{X} 1$ and $\Delta \sigma^{*}(\mathrm{R}-\mathrm{X} 2)$ with a slope very closed to 1.0 . That is to say, all the charge that the donor orbital had lost was consequently gained by the acceptor orbital.

These results are consistent with the loss of electron density shown in the analysis of the $L(\mathbf{r})$ function on the VSCC of the halogen atom and by the electron density shifts maps (Figure 2A).

Molecular Electrostatic Potentials. The molecular electrostatic potential (MEP) is a measure of the electrostatic interaction between a positive test charge and the undisturbed molecule, without considering the induction, and dispersion effects. ${ }^{51}$ To analyze the electrostatic behavior on halogen $\mathrm{X}$, the maximum $\left(V_{\mathrm{S}, \max }\right)$ and minimum $\left(V_{\mathrm{S}, \text { min }}\right)$ electrostatic potentials on the 0.001 au electron density isosurface have been located (Figure 5). In all the molecules, $V_{\mathrm{S}, \max }$ are found in the two extremes of the molecule along the symmetry axes. In addition, in the interhalogen molecules a torus of local $V_{\mathrm{S} \text {,max }}$ is

Table 4. Natural Bond Orbital Analysis for $\mathrm{R}-\mathrm{X} \cdots \mathrm{X}-\mathrm{R}$ Complexes, Occupation Numbers of Selected Molecular Orbitals, and Second-Order Perturbation Energies $E^{(2)}(\text { Donor } \rightarrow \text { Acceptor) })^{a, b, c}$

\begin{tabular}{|c|c|c|c|c|c|}
\hline \multirow[b]{2}{*}{ complexes } & \multicolumn{3}{|c|}{ population } & \multicolumn{2}{|c|}{ energies $E^{(2)}$} \\
\hline & LP(1)X1 & LP(2)X1 & $\sigma^{*}(\mathrm{R}-\mathrm{X} 2)$ & $\mathrm{LP}(1) \mathrm{X} 1 \rightarrow \sigma^{*}(\mathrm{R}-\mathrm{X} 2)$ & $\mathrm{LP}(2) \mathrm{X} 1 \rightarrow \sigma^{*}(\mathrm{R}-\mathrm{X} 2)$ \\
\hline $\mathrm{HCl} \cdots \mathrm{ClH}$ & 2.00 & 2.00 & 0.001 & 0.5 & 1.5 \\
\hline $\mathrm{ClCl} \cdots \mathrm{ClCl}$ & 2.00 & 1.98 & 0.008 & 1.6 & 4.4 \\
\hline $\mathrm{FCl} \cdots \mathrm{ClF}$ & 2.00 & 1.99 & 0.015 & 1.1 & 7.4 \\
\hline $\mathrm{HBr} \cdots \mathrm{BrH}$ & 2.00 & 2.00 & 0.004 & 0.5 & 2.8 \\
\hline $\mathrm{ClBr} \cdots \mathrm{BrCl}$ & 2.00 & 1.97 & 0.033 & 2.4 & 14.3 \\
\hline $\mathrm{BrBr} \cdots \mathrm{BrBr}$ & 2.00 & 1.97 & 0.033 & 2.6 & 14.0 \\
\hline $\mathrm{FBr} \cdots \mathrm{BrF}$ & 2.00 & 1.93 & 0.068 & 4.5 & 32.3 \\
\hline $\mathrm{HI} \cdots \mathrm{IH}$ & 2.00 & 1.99 & 0.008 & 0.6 & 4.7 \\
\hline $\mathrm{II} \cdots \mathrm{II}$ & 2.00 & 1.94 & 0.064 & 5.3 & 26.4 \\
\hline $\mathrm{Br}+\cdots \mathrm{IBr}$ & 2.00 & 1.92 & 0.081 & 5.7 & 32.8 \\
\hline $\mathrm{ClI} \cdots \mathrm{ICl}$ & 2.00 & 1.91 & 0.087 & 5.9 & 35.6 \\
\hline $\mathrm{FI} \cdots \mathrm{IF}$ & 2.00 & 1.83 & 0.164 & 10.2 & 81.0 \\
\hline
\end{tabular}

${ }^{a}$ Energies in $\mathrm{kJ} / \mathrm{mol}$ and occupation numbers in $e .{ }^{b}$ Due to symmetry NBO analysis is shown only for Donor(monomer-1) $\rightarrow$ Acceptor $($ monomer2). The interactions Donor(monomer-2) $\rightarrow$ Acceptor(monomer-1) are identical. ${ }^{c}$ The $L P(1)$ orbital axis is perpendicular to $\sigma_{R-X}$ and is in the plane of the complex, whereas the $\mathrm{LP}(2)$ orbital axis is perpendicular to $\sigma_{\mathrm{R}-\mathrm{X}}$ and is perpendicular to the plane of the complex. 


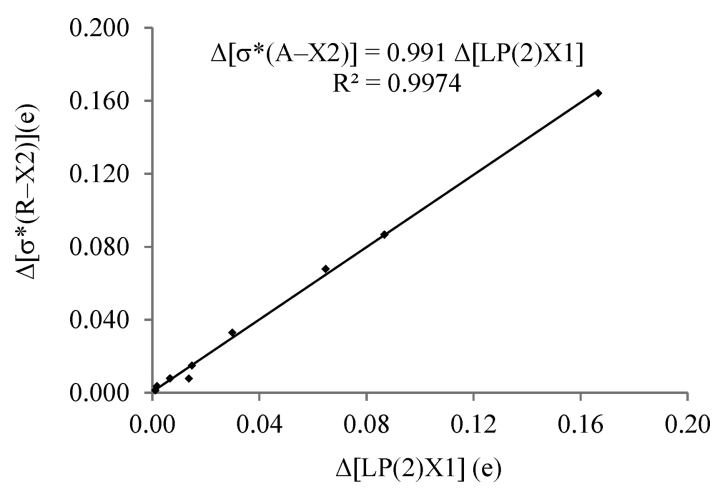

Figure 4. Linear correlation between the change of the electron population at lone pair of a $\mathrm{X}$ atom, $\Delta \mathrm{LP}(2) \mathrm{X} 1$, vs the change of the electron population of the antibonding orbital, $\Delta \sigma^{*}(\mathrm{R}-\mathrm{X} 2)$.

found in the equatorial region between the two halogen atoms (Figure S2 in the Supporting Information). The $V_{\mathrm{S} \text {,min }}$ regions are around the halogen atoms. In Table 5 are gathered the values of the maximum and minimum electrostatic potentials $\left(V_{\mathrm{S}, \max }\right.$ and $\left.V_{\mathrm{S}, \min }\right)$ associated with the halogen $\sigma$-hole and lone pairs, respectively. $V_{\mathrm{S} \text {, max }}$ values show the expected trends of increasing values with the electron-withdrawing capacity of the $\mathrm{R}$ atom $(\mathrm{H}<\mathrm{Cl}<\mathrm{F})$ and with the size of the halogen $(\mathrm{Cl}<\mathrm{Br}$ $<\mathrm{I})$. Moreover, the $V_{\mathrm{S} \text {,min }}$ values decrease with the size of the halogen $(\mathrm{I}>\mathrm{Br}>\mathrm{Cl}$ ) and with the capacity electronwithdrawing of $\mathrm{R}$ atom $(\mathrm{F}>\mathrm{Cl}>\mathrm{H})$. These last results are consistent with the interaction energies and $\mathrm{X} \cdots \mathrm{X}$ intermolecular distances shown in Table 1 and clearly show that electrostatic interactions $V_{\mathrm{S} \text {,min }} \rightarrow \sigma$-hole play a key role in the nature and strength of these unusual $\mathrm{X} \cdots \mathrm{X}$ interactions.

It is interesting to notice that in the case of the FI molecule the $V_{\mathrm{S} \text {,min }}$ on the iodine atom present a positive value.

\section{CONCLUSIONS}

$\mathrm{Ab}$ initio calculations have been carried out on unusual type I halogen bonding $\mathrm{R}-\mathrm{X} 1 \cdots \mathrm{X} 2-\mathrm{R}$ interactions (with $\mathrm{R}=-\mathrm{H}$, $-\mathrm{Cl},-\mathrm{F}$ and $\mathrm{X}=\mathrm{Cl}, \mathrm{Br}, \mathrm{I})$, to determine their structures, interaction energies, and natures of the halogen-halogen contacts. These calculations predict that these molecular complexes are always more stable than the separated $\mathrm{R}-\mathrm{X}$ species.

The geometrical parameters reveal that $\mathrm{R}-\mathrm{X} 1 \cdots \mathrm{X} 2-\mathrm{R}$ complexes have a planar structure, with $\mathrm{X} \cdots \mathrm{X}$ intermolecular distances substantially shorter than the sum of the van der
Table 5. Maximum $\left(V_{\mathrm{S}, \max }\right)$ and Minimum $\left(V_{\mathrm{S}, \min }\right)$ Electrostatic Potentials on Halogen Atom $\mathrm{X}^{a}$

$\begin{array}{crr}\text { molecule R-X } & V_{S, \max } & V_{S, \text { min }} \\ \mathrm{H}-\mathrm{Cl} & 26.8 & -44.4 \\ \mathrm{Cl}-\mathrm{Cl} & 108.8 & -11.3 \\ \mathrm{~F}-\mathrm{Cl} & 186.6 & -0.8 \\ \mathrm{H}-\mathrm{Br} & 59.4 & -39.3 \\ \mathrm{Cl}-\mathrm{Br} & 156.5 & -8.4 \\ \mathrm{Br}-\mathrm{Br} & 125.0 & -17.0 \\ \mathrm{~F}-\mathrm{Br} & 222.2 & -2.1 \\ \mathrm{H}-\mathrm{I} & 87.4 & -31.4 \\ \mathrm{I}-\mathrm{I} & 130.6 & -16.8 \\ \mathrm{Br}-\mathrm{I} & 168.8 & -11.3 \\ \mathrm{Cl}-\mathrm{I} & 190.8 & -5.9 \\ \mathrm{~F}-\mathrm{I} & 235.6 & 0.8\end{array}$

${ }^{a}\left(V_{\mathrm{S}, \max }\right)$ : reflect the $\sigma$-hole of the halogen $\mathrm{X} .\left(V_{\mathrm{S}, \min }\right):$ reflect the lone pairs of the halogen $\mathrm{X}$. All values in $\mathrm{kJ} \mathrm{mol}^{-1}$.

Waals radii of $\mathrm{X} 1$ and $\mathrm{X} 2$ atoms, and equilibrium $\mathrm{R}-\mathrm{X} 1 \cdots \mathrm{X} 2$ angles close to $150^{\circ}$.

According to AIM, NBO, and MEP analyses, the formation of the studied complexes results from the atomic interaction between the halogen atoms $\mathrm{X} 1$ and $\mathrm{X} 2$. The geometry and stability of these complexes is mainly due to electrostatic interactions lump $(\mathrm{X} 1) \rightarrow$ hole $(\mathrm{X} 2)$ and $\operatorname{lump}(\mathrm{X} 2) \rightarrow \operatorname{hole}(\mathrm{X} 1)$ [or equivalently $\left[V_{\mathrm{S}, \min }(\mathrm{X} 1) \rightarrow V_{\mathrm{S}, \max }(\mathrm{X} 2)\right.$ and $V_{\mathrm{S}, \min }(\mathrm{X} 2) \rightarrow$ $\left.V_{\mathrm{S}, \max }(\mathrm{X} 1)\right]$ and charge transfers $\mathrm{LP}(\mathrm{X} 1) \rightarrow \sigma^{*}(\mathrm{R}-\mathrm{X} 2)$ and $\mathrm{LP}(\mathrm{X} 2) \rightarrow \sigma^{*}(\mathrm{R}-\mathrm{X} 1)$. In other words, these findings suggest that the electrostatic interactions and the charge transfer play a substantial role in determining the optimal geometry of these complexes, as in conventional XBs.

Finally, according to LMOEDA methodology the most important stabilization term corresponds to the dispersion followed by the electrostatic term.

\section{ASSOCIATED CONTENT}

S Supporting Information

BSSE test calculation, $L(\mathbf{r})$ function in the isolated $\mathrm{BrF}$, and MEP on the 0.001 au electron density isosurface of all the monomers. This material is available free of charge via the Internet at http://pubs.acs.org.

\section{AUTHOR INFORMATION} Corresponding Author

*D. J. R. Duarte. E-mail: djr_duarte@hotmail.com. Tel/fax: +54 3794473930 .
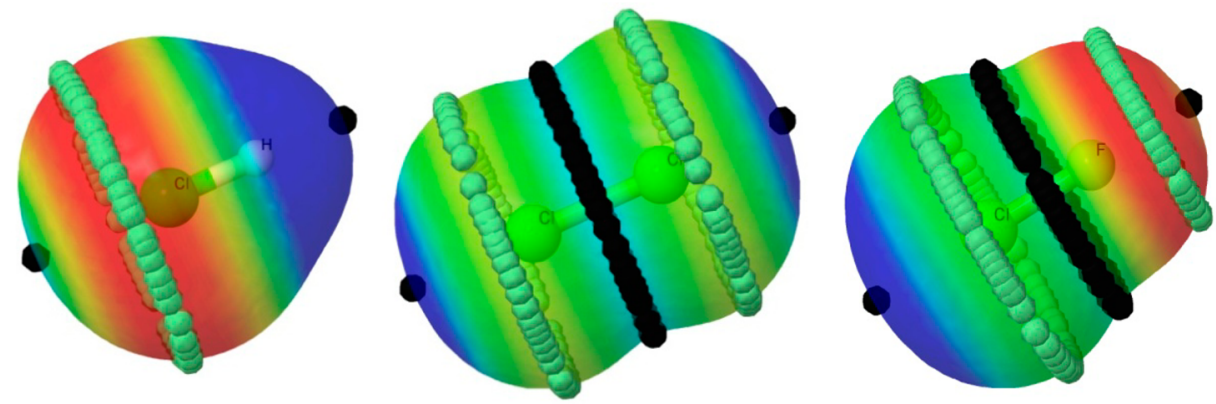

Figure 5. Molecular electrostatic potential on the 0.001 au electron density isosurface of the $\mathrm{ClH}, \mathrm{Cl}_{2}$, and $\mathrm{ClF}$ molecules. The range of colors between red and blue corresponds to the values of the MEP between -39 and $+39 \mathrm{~kJ} / \mathrm{mol}$, respectively. The light green and black dots represents

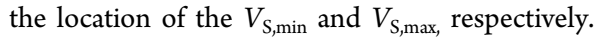




\section{Notes}

The authors declare no competing financial interest.

\section{ACKNOWLEDGMENTS}

D. J. R. Duarte and N. M. Peruchena acknowledge SECYT UNNE and CONICET for financial support. The authors also acknowledge the use of CPUs from the High Performance Computing Center of the Northeastern of Argentina (CECONEA). This work was supported by the Grants PIP 095 CONICET and 2010F023 SECYT-UNNE. I. Alkorta acknowledge the Spanish Ministerio de Economía y Competitividad (CTQ2012-35513-C02-02) and Comunidad Autónoma de Madrid (S2013/MIT-2841, Fotocarbon) for financial support.

\section{REFERENCES}

(1) Desiraju, G. R.; Ho, P. S.; Kloo, L.; Legon, A. C.; Marquardt, R.; Metrangolo, P.; Politzer, P.; Resnati, G.; Rissanen, K. Definition of the Halogen Bond (IUPAC Recommendations 2013). Pure Appl. Chem. 2013, 8, 1711-1713.

(2) Riley, K. E.; Murray, J. S.; Politzer, P.; Concha, M. C.; Hobza, P. $\mathrm{Br} \cdots \mathrm{O}$ Complexes as Probes of Factors Affecting Halogen Bonding: Interactions of Bromobenzenes and Bromopyrimidines with Acetone. J. Chem. Theor. Comput. 2009, 5, 155-163.

(3) Riley, K. E.; Murray, J. S.; Fanfrlík, J.; Řezáč, J.; Solá, R. J.; Concha, M. C.; Ramos, F. M.; Politzer, P. Halogen Bond Tunability I: the Effects of Aromatic Fluorine Substitution on the Strengths of Halogen-Bonding Interactions Involving Chlorine, Bromine, and Iodine. J. Mol. Model. 2011, 17, 3309-3318.

(4) Politzer, P.; Murray, J. S.; Clark, T. Halogen Bonding and Other $\sigma$-Hole Interactions: a Perspective. Phys. Chem. Chem. Phys. 2013, 15, 11178-11189.

(5) Desiraju, G. R.; Parthasarathy, R. The Nature of Halogen *. Halogen Interactions: Are Short Halogen Contacts Due to Specific Attractive Forces or Due to Close Packing of Nonspherical Atoms? J. Am. Chem. Soc. 1989, 111, 8725-8726.

(6) Jagarlapudi, A. R.; Sarma, P.; Desiraju, G. R. The role of $\mathrm{Cl} \cdots \mathrm{Cl}$ and $\mathrm{C}-\mathrm{H} \cdots \mathrm{O}$ Interactions in the Crystal Engineering of $4 \AA$. ShortAxis Structures. Acc. Chem. Res. 1986, 19, 222-228.

(7) Reddy, C. M.; Kirchner, M. T.; Gundakaram, R. V.; Padmanabhan, K. A.; Desiraju, G. R. Isostructurality, Polymorphism and Mechanical Properties of Some Hexahalogenated Benzenes: The Nature of Halogen $\cdots$ Halogen Interactions. Chem.-Eur. J. 2006, 12, 2222-2234.

(8) Ramasubbu, N.; Parthasarathy, R.; Murray-Rust, P. Angular Preferences of Intermolecular Forces Around Halogen Centers: Preferred Directions of Approach of Electrophiles and Nucleophiles Around Carbon-Calogen Bond. J. Am. Chem. Soc. 1986, 108, 43084314.

(9) Bach, A.; Lentz, D.; Luger, P. Charge Density and Topological Analysis of Pentafluorobenzoic Acid. J. Phys. Chem. A 2001, 105, 7405-7412.

(10) Matta, C. F.; Castillo, N.; Boyd, R. J. Characterization of a Closed Shell Fluorine-Fluorine Bonding Interaction in Aromatic Compounds on the Basis of the Electron Density. J. Phys. Chem. A 2005, 109, 3669-3681.

(11) Bosch, E.; Barnes, C. L. Triangular Halogen-Halogen-Halogen Interactions as a Cohesive Force in the Structures of Trihalomesitylenes. Cryst. Growth Des. 2002, 2, 299-302.

(12) Broder, C. K.; Howard, A. J.; Wilson, C. C.; Allen, F. H.; Jetti, R. K.; Nangia, A.; Desiraju, G. R. Halogen Trimer Synthons in Crystal Engineering: Low-Temperature X-Ray and Neutron Diffraction Study of the 1:1 Complex of 2,4,6-tris(4-chlorophenoxy)-1,3,5-triazine with Tribromobenzene. Acta Crystallogr., Sect. B 2000, 56, 1080-1084.

(13) Matsumoto, A.; Tanaka, T.; Tsubouchi, T.; Tashiro, K.; Saragai, S.; Nakamoto, Sh. Crystal Engineering for Topochemical Polymerization of Muconic Esters Using Halogen-Halogen and $\mathrm{CH} / \pi$
Interactions as Weak Intermolecular Interactions. J. Am. Chem. Soc. 2002, 124, 8891-8902.

(14) Duarte, D. J. R.; Sosa, G. L.; Peruchena, N. M. Nature of halogen bonding. A Study Based on the Topological Analysis of the Laplacian of the Electron Charge Density and an Energy Decomposition Analysis. J. Mol. Model. 2013, 19, 2035-2041.

(15) Duarte, D. J. R.; Angelina, E. L.; Peruchena, N. M. On the Strength of the Halogen Bonds: Mutual Penetration, Atomic Quadrupole Moment and Laplacian Distribution of the Charge Density Analyses. Comput. Theor. Chem. 2012, 998, 64-172.

(16) Eskandari, K.; Zariny, H. Halogen Bonding: A Lump-Hole Interaction. Chem. Phys. Lett. 2010, 492, 9-13.

(17) Martinez Amezaga, N. J.; Pamies, S. C.; Peruchena, N. M.; Sosa, G. L. Halogen Bonding: A Study Based on the Electronic Charge Density. J. Phys. Chem. A 2010, 114, 552-562.

(18) Awwadi, F.; Willett, R. D.; Peterson, K. A.; Twamley, B. The Nature of Halogen $\cdots$ Halogen Synthons: Crystallographic and Theoretical Studies. Chem.-Eur. J. 2006, 12, 8952-8960.

(19) Del Bene, J. E.; Alkorta, I.; Sanchez-Sanz, G. Elguero, ${ }^{31} \mathrm{P}_{-}{ }^{31} \mathrm{P}$ Spin-Spin Coupling Constants for Pnicogen Homodimers. Chem. Phys. Lett. 2011, 512, 184-187.

(20) Zahn, S.; Frank, R.; Hey-Hawkins, E.; Kirchner, B. Pnicogen Bonds: A New Molecular Linker? Chem.-Eur. J. 2011, 17, 60346038.

(21) Eskandari, K.; Mahmoodabadi, N. Pnicogen Bonds: A Theoretical Study Based on the Laplacian of Electron Density. J. Phys. Chem. A 2013, 117, 13018-13024.

(22) Møller, C.; Plesset, M. S. Note on an Approximation Treatment for Many-electron Systems. Phys. Rev. 1934, 46, 618-622.

(23) Dunning, T. H., Jr. Gaussian Basis Sets for Use in Correlated Molecular Calculations. I. The Atoms Boron Through Neon and Hydrogen. J. Chem. Phys. 1989, 90, 1007-23.

(24) Weigend, F.; Ahlrichs, R. Balanced Basis Sets of Split Valence, Triple Zeta Valence and Quadruple Zeta Valence Quality for H to Rn: Design and Assessment of Accuracy. Phys. Chem. Chem. Phys. 2005, 7, 3297-305.

(25) Mentel, L. M.; Baerends, E. J. Can the Counterpoise Correction for Basis Set Superposition Effect Be Justified? J. Chem. Theory Comput. 2014, 10, 252-267.

(26) Alkorta, I.; Elguero, J.; Grabowski, S. J. Pnicogen and Hydrogen Bonds: Complexes Between $\mathrm{PH}_{3} \mathrm{X}^{+}$and $\mathrm{PH}_{2} \mathrm{X}$ Systems. Phys. Chem. Chem. Phys. 2015, 17, 3261-3272.

(27) Su, P.; Li, H. Energy Decomposition Analysis of Covalent Bonds and Intermolecular Interactions. J. Chem. Phys. 2009, 131, 014102.

(28) Chen, W.; Gordon, M. S. Energy Decomposition Analyses for Many-Body Interaction and Application to Water Clusters. J. Phys. Chem. 1996, 100, 14316 ().

(29) Schmidt, M. W.; Baldridge, K. K.; Boatz, J. A.; Elbert, S. T.; Gordon, M. S.; Jensen, J. H.; Koseki, S.; Matsunaga, N.; Nguyen, K. A.; $\mathrm{Su}, \mathrm{S}$; ; et al. General Atomic and Molecular Electronic Structure System. J. Comput. Chem. 1993, 14, 1347-1363.

(30) (a) Bader, R. F. W. Atoms in Molecules. A Quantum Theory; Clarendon: Oxford, U.K., 1990. (b) Popelier, P. Atoms in Molecules, an Introduction; Prentice-Hall: Manchester, U.K., 2000. (c) Matta, C. F.; Boyd, R. J. The Quantum Theory of Atoms in Molecules: from Solid State to DNA and Drug Design; Wiley-VCH: Weinheim, 2007.

(31) Keith, Todd A. AIMAll (Version 11.12.19); TK Gristmill Software, Overland Park KS, 2011; aim.tkgristmill.com.

(32) (a) Becke, A. D. Density functional thermochemistry. III. The role of exact exchange. J. Chem. Phys. 1993, 98, 5648-5652. (b) Lee, C.; Yang, W.; Parr, R. G. Development of the Colle-Salvetti Correlation-Energy Formula into a Functional of the Electron Density. Phys. Rev. B 1988, 37, 785-789.

(33) Raghavachari, K.; Binkley, J. S.; Seeger, R.; Pople, J. A. SelfConsistent Molecular Orbital Methods. 20. Basis Set for Correlated Wave-Functions. J. Chem. Phys. 1980, 72, 650-54. 
(34) Reed, A. E.; Curtiss, L. A.; Weinhold, F. Intermolecular Interactions from a Natural Bond Orbital, Donor-Acceptor Viewpoint. Chem. Rev. 1988, 88, 899-926.

(35) Glendening, E. D.; Badenhoop, J. K.; Reed, A. E.; Carpenter, J. E.; Weinhold, F. NBO Version 3.1; Theoretical Chemistry Institute, University of Wisconsin: Madison, WI.

(36) Frisch, M. J.; Trucks, G. W.; Schlegel, H. B.; Scuseria, G. E.; Robb, M. A.; Cheeseman, J. R.; Montgomery, J. A., Jr.; Vreven, T.; Kudin, K. N.; Burant, J. C.; Millam, J. M.; Iyengar, S. S.; Tomasi, J.; Barone, V.; Mennucci, B.; Cossi, M.; Scalmani, G.; Rega, N.; Petersson, G. A.; Nakatsuji, H.; Hada, M.; Ehara, M.; Toyota, K.; Fukuda, R.; Hasegawa, J.; Ishida, M.; Nakajima, T.; Honda, Y.; Kitao, O.; Nakai, H.; Klene, M.; Li, X.; Knox, J. E.; Hratchian, H. P.; Cross, J. B.; Adamo, C.; Jaramillo, J.; Gomperts, R.; Stratmann, R. E.; Yazyev, O.; Austin, A. J.; Cammi, R.; Pomelli, C.; Ochterski, J. W.; Ayala, P. Y.; Morokuma, K.; Voth, G. A.; Salvador, P.; Dannenberg, J. J.; Zakrzewski, G.; Dapprich, S.; Daniels, A. D.; Strain, M. C.; Farkas, O.; Malick, D. K.; Rabuck, A. D.; Raghavachari, K.; Foresman, J. B.; Ortiz, J. V.; Cui, Q.; Baboul, A. G.; Clifford, S.; Cioslowski, J.; Stefanov, B. B.; Liu, G.; Liashenko, A.; Piskorz, P.; Komaromi, I.; Martin, R. L.; Fox, D. J.; Keith, T.; Al-Laham, M. A.; Peng, C. Y.; Nanayakkara, A.; Challacombe, M.; Gill, P. M. W.; Johnson, B.; Chen, W.; Wong, M. W.; Gonzalez, C.; Pople, J. A. Gaussian 03, revision D.01; Gaussian, Inc. and Theoretical Chemistry Institute, University of Wisconsin: Wallingford, CT, and Madison, WI, 2004.

(37) Lu, T.; Chen, F. Multiwfn: A Multifunctional Wavefunction Analyzer. J. Comput. Chem. 2012, 33, 580-592.

(38) Bondi, A. van der Waals Volumes and Radii. J. Phys. Chem. 1964, 68, 441-451.

(39) Powell, B. M.; Heal, K. M.; Torrie, B. H. The Temperature Dependence of the Crystal Structures of the Solid Halogens, Bromine and Chlorine. Mol. Phys. 1984, 53, 929-939.

(40) van Bolhuis, F.; Koster, P. B.; Migchelsen, T. Refinement of the Crystal Structure of Iodine at $110 \mathrm{~K}$. Acta Crystallogr. 1967, 23, 90-91.

(41) Stone, A. J. Are Halogen Bonded Structures Electrostatically Driven? J. Am. Chem. Soc. 2013, 135, 7005-7009.

(42) Tsuzuki, S.; Wakisaka, A.; Ono, T.; Sonoda, T. Magnitude and Origin of the Attraction and Directionality of the Halogen Bonds of the Complexes of $\mathrm{C}_{6} \mathrm{~F}_{5} \mathrm{X}$ and $\mathrm{C}_{6} \mathrm{H}_{5} \mathrm{X}(\mathrm{X}=\mathrm{I}, \mathrm{Br}, \mathrm{Cl}$ and $\mathrm{F})$ with Pyridine. Chem.-Eur. J. 2012, 18, 951-960.

(43) Rozas, I.; Alkorta, I.; Elguero, J. Behavior of Ylides Containing $\mathrm{N}, \mathrm{O}$, and C Atoms as Hydrogen Bond Acceptors. J. Am. Chem. Soc. 2000, 122, 11154-11161.

(44) Lv, H.; Zhuoa, H. Y.; Lia, Q. Z.; Yanga, X.; Lia, W. Z.; Cheng, J. B. Halogen Bonds with N-Heterocyclic Carbenes as Halogen Acceptors: a Partially Covalent Character. Mol. Phys. 2014, 112, 3024-3032.

(45) Sanchez-Sanz, G.; Trujillo, C.; Alkorta, I.; Elguero, J. Electron Density Shift Description of non-Bonding Intramolecular Interactions. Comput. Theor. Chem. 2012, 991, 124-133.

(46) Popelier, P. L. A. On the Full Topology of the Laplacian of the Electron Density. Coord. Chem. Rev. 2000, 197, 169-189.

(47) Eskandari, K. Characteristics of Beryllium Bonds; a QTAIM study. J. Mol. Model. 2012, 18, 3481-3487.

(48) Alikhani, E.; Fuster, F.; Madebene, B.; Grabowski, S. J. Topological Reaction Sites-Very Strong Chalcogen Bonds. Phys. Chem. Chem. Phys. 2014, 16, 2430-2442.

(49) Alkorta, I.; Elguero, J.; Del Bene, J. E. Pnicogen-Bonded Cyclic Trimers $\left(\mathrm{PH}_{2} \mathrm{X}\right)_{3}$ with $\mathrm{X}=\mathrm{F}, \mathrm{Cl}, \mathrm{OH}, \mathrm{NC}, \mathrm{CN}, \mathrm{CH}_{3}, \mathrm{H}$, and $\mathrm{BH}_{2} . J$. Phys. Chem. A 2013, 117, 4981-4987.

(50) Politzer, P.; Lane, P.; Concha, M. C.; Ma, Y.; Murray, J. S. An Overview of Halogen Bonding. J. Mol. Model. 2007, 13, 305-311.

(51) Naray-Szabo, G.; Ferenczy, G. G. Molecular Electrostatics. Chem. Rev. 1995, 95, 829-847. 